\title{
EFEITO DA MAGNESITA NO PROCESSO DE SINTERIZAÇÃO *
}

\author{
Thiago Pinto Silva ${ }^{1}$ \\ Beatriz Fausta Gandra² \\ Wilhan Nunes da Costa ${ }^{3}$
}

\section{Resumo}

Este estudo teve como objetivo investigar o efeito da substituição da dolomita por magnesita como fonte de $\mathrm{MgO}$ no processo de sinterização. Em testes realizados em escala piloto, observou-se que a utilização de magnesita eleva a resistência mecânica do sínter. A diferença de resistência foi decorrente da formação de uma solução sólida entre magnésio e ferro durante a sinterização. No caso da dolomita, que é fonte tanto de cálcio quanto de magnésio, a solução sólida Mg-Fe promove o encapsulamento do cálcio no seu interior, o que dificulta a formação das fases mineralógicas que promovem o endurecimento do sínter. Assim, a participação do cálcio na formação das fases ligantes é inibida, limitando a resistência mecânica obtida. A magnesita, por sua vez, não apresenta cálcio em sua constituição, sendo esse elemento adicionado via calcário. Dessa forma, o efeito do encapsulamento do cálcio não ocorre, havendo grande disponibilidade desse elemento para a formação de fases ligantes, permitindo a obtenção de níveis mais elevados de resistência mecânica do sínter. Portanto, a substituição da dolomita pela magnesita mostrou-se viável, desde que a granulometria seja similar à da dolomita, com grande potencial de melhora produtiva da sinterização industrial.

Palavras-chave: Magnesita; Dolomita; Minério de ferro; Sinterização.

\section{EFFECT OF THE MAGNESITE IN THE SINTERING PROCESS}

\begin{abstract}
This study aimed to investigate the effect of the substitution of dolomite by magnesite in the sintering process. In pilot scale, it was observed that the use of magnesite increases the sinter's mechanical resistance. The difference in strength was due to the solid solution's formation between $\mathrm{Mg}$ and Fe during sintering. In the dolomite's case, which is a source of both calcium and magnesium, the solid solution Mg-Fe promotes the encapsulation of the calcium inside it, which makes tough to form the mineralogical phases that promote the hardening of the sinter. Thus, the calcium's participation in the formation of the binding phases is inhibited, limiting the mechanical resistance. Magnesite, on the other hand, does not have calcium in its constitution, being this element added by limestone. Thus, the calcium encapsulation effect does not occur, and there is great availability of this element for the binding phases formation, allowing higher levels of sinter's mechanical resistance. Therefore, the dolomite's substitution by magnesite proved viable, since the size distribution be similar each other, with great potential for productive improvement of industrial sintering.
\end{abstract}

Keywords: Magnesite; Dolomite; Iron ore; Sintering.

\footnotetext{
Membro da ABM; Eng. Metalurgista, MBA, Pesquisador, Centro de Pesquisa Usiminas; Ipatinga, MG, Brasil. Membro da ABM; Eng. Metalurgista, M.Sc., Pesquisadora, Centro de Pesquisa Usiminas; Ipatinga, MG, Brasil.

3 Técnico em Metalurgia, Técnico em Pesquisa, Centro de Pesquisa Usiminas; Ipatinga, MG, Brasil.
} 


\section{INTRODUÇÃO}

O óxido de magnésio é adicionado ao sínter para alterar as propriedades da escória primária (zona coesiva) e final no alto-forno [1], controlando o Índice de Degradação durante Redução (RDI), conforme pontuado por Inazumi [2], apesar de haver relatos de prejuízos na resistência mecânica do sínter [3]. Além disso, a fonte mineral deste composto é outro fator determinante para o comportamento do processo e dos consumos específicos.

Atualmente, a fonte de $\mathrm{MgO}$ utilizada nas sinterizações da Usiminas é a dolomita. O seu uso foi possível em virtude da deterioração química (elevação da sílica) dos minérios. No trabalho desenvolvido em 2009, Scudeller [4] mostrou a viabilidade técnica da substituição do serpentinito (fonte de $\mathrm{MgO}$ e $\mathrm{SiO}_{2}$ ) pela dolomita (fonte de $\mathrm{MgO}$ e $\mathrm{CaO}$ ), reduzindo o teor de sílica que fora elevado no sínter, sem alterar os indicadores produtivos.

Outra alternativa como fonte mineral de magnésio é a magnesita. Neste contexto, foi avaliado, em escala piloto, o efeito da substituição da dolomita pela magnesita no processo de sinterização.

\section{MATERIAIS E MÉTODOS}

\subsection{Composições químicas e granulométricas das matérias-primas}

Foram caracterizadas quatro amostras de magnesitas e uma de dolomita, cujas características químicas e granulométricas são apresentadas nas Tabelas 1 e 2 . Essas amostras foram usadas como fonte de $\mathrm{MgO}$ na fabricação de cinco sínteres. Além disso, apresentam-se as características do calcário, cuja proporção também foi alterada em razão da basicidade ter sido considerada invariável. Na Figura 1 são mostrados os termogramas dessas fontes.

Tabela 1. Composição química das fontes de $\mathrm{CaO}$ e $\mathrm{MgO}$ (\% em massa)

\begin{tabular}{c|c|c|c|c|c|c|c|c|c}
\hline \multicolumn{2}{c|}{ Fonte de $\mathbf{M g O}$} & $\mathbf{M g O}$ & $\mathbf{C a O}$ & $\mathbf{P P C}$ & $\mathbf{S i O}_{2}$ & $\mathbf{A l}_{2} \mathbf{O}_{3}$ & $\mathbf{F e}_{\text {total }}$ & $\mathbf{F e O}$ & $\mathbf{M n O}$ \\
\hline \multirow{4}{*}{ Magnesita } & $\mathrm{A}$ & 45,8 & 0,4 & 48,9 & 4,0 & 0,6 & 0,3 & - & 0,2 \\
\cline { 2 - 11 } & $\mathrm{B}$ & 43,6 & 0,5 & 46,0 & 3,9 & 0,5 & 3,1 & 0,3 & 0,4 \\
\cline { 2 - 11 } & $\mathrm{C}$ & 44,7 & 0,3 & 49,8 & 2,0 & 0,5 & 1,2 & 0,2 & 0,4 \\
\cline { 2 - 10 } & $\mathrm{D}$ & 44,4 & 0,4 & 46,9 & 6,4 & 0,6 & 0,3 & 0,2 & 0,1 \\
\hline \multicolumn{2}{c}{ Dolomita } & 16,9 & 35,5 & 45,0 & 2,1 & 0,4 & 0,3 & 0,2 & - \\
\hline \multicolumn{2}{c}{ Calcário } & 0,3 & 55,4 & 42,7 & 1,0 & 0,2 & 0,3 & - & - \\
\hline
\end{tabular}

Tabela 2. Distribuição granulométrica das fontes de $\mathrm{CaO}$ e $\mathrm{MgO}$ (\% em massa)

\begin{tabular}{c|c|c|c|c|c|c}
\hline \multicolumn{2}{c}{ Fonte de MgO } & $\mathbf{> 6 , 3 5} \mathbf{~ m m}$ & $\mathbf{( 6 , 3 5 ~ 1 ) ~} \mathbf{m m}$ & $\mathbf{( 1 \sim 0 , 5 )} \mathbf{~ m m}$ & $\mathbf{( 0 , 5 ~ 0 , 1 0 5 )} \mathbf{~ m m}$ & $<\mathbf{0 , 1 0 5} \mathbf{~ m m}$ \\
\hline \multirow{4}{*}{ Magnesita } & $\mathrm{A}$ & 0,04 & 39,15 & 35,24 & 23,68 & 1,89 \\
\cline { 2 - 7 } & $\mathrm{B}$ & 0 & 71,10 & 22,81 & 5,54 & 0,55 \\
\cline { 2 - 7 } & $\mathrm{C}$ & 0 & 63,39 & 28,29 & 7,94 & 0,38 \\
\cline { 2 - 7 } & $\mathrm{D}$ & 0 & 0 & 0 & 12,64 & 87,36 \\
\hline \multicolumn{2}{c}{ Dolomita } & 1,25 & 68,65 & 14,45 & 10,37 & 5,28 \\
\hline \multicolumn{2}{c}{ Calcário } & 0,71 & 62,84 & 8,92 & 7,16 & 20,37 \\
\hline
\end{tabular}




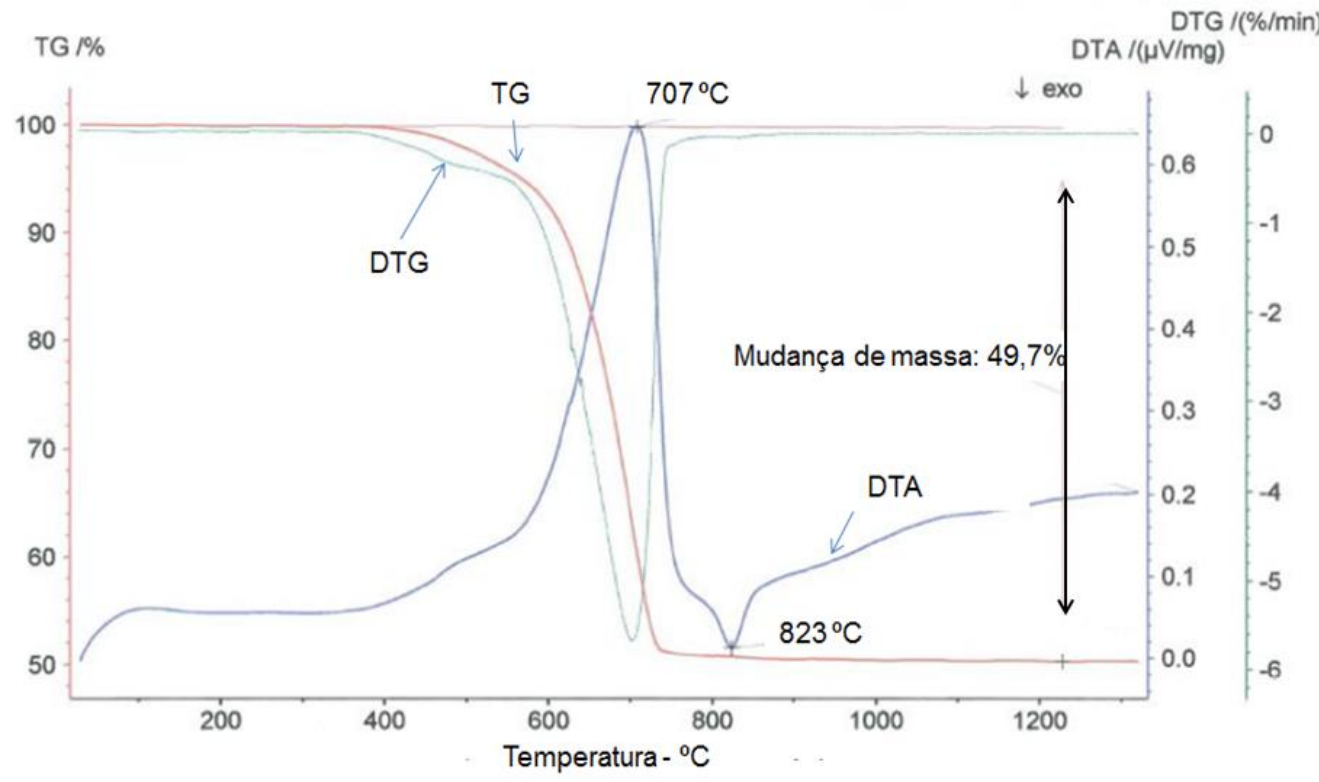

(a) Magnesita

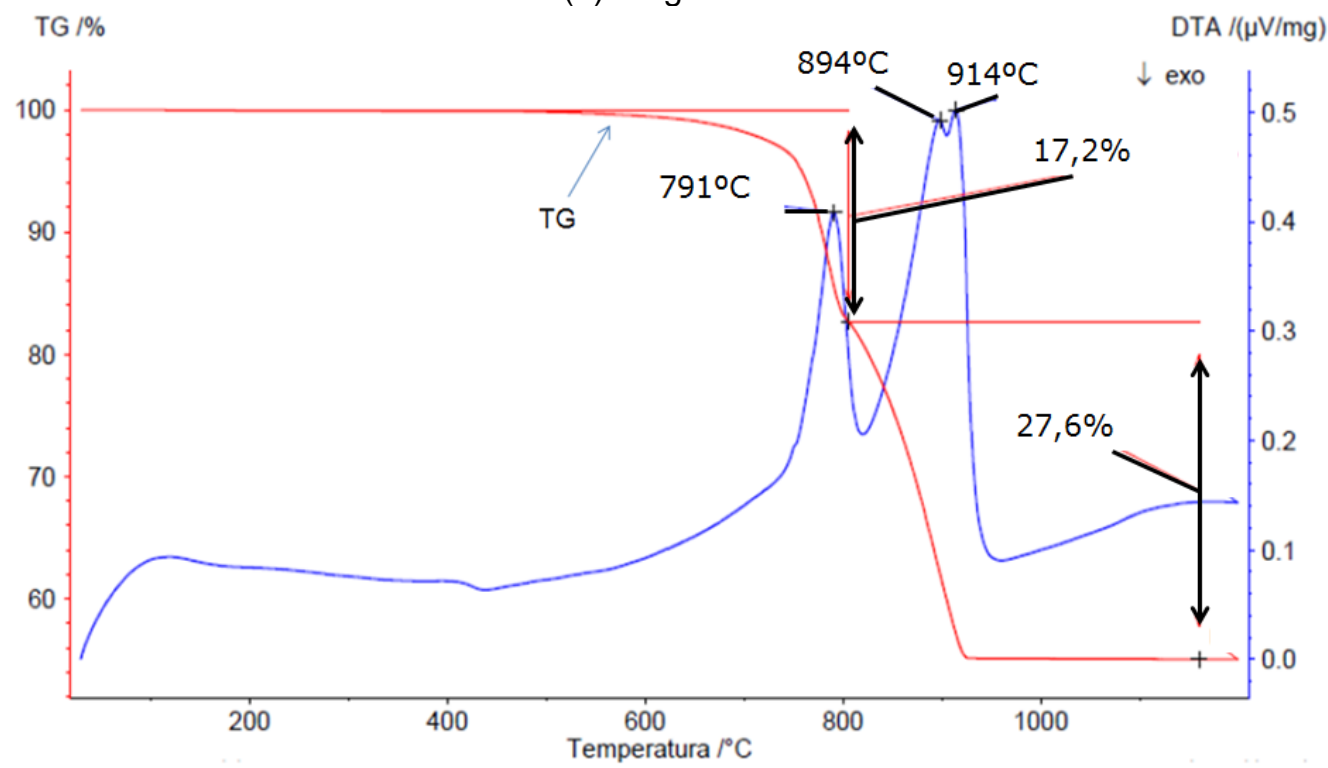

b) Dolomita

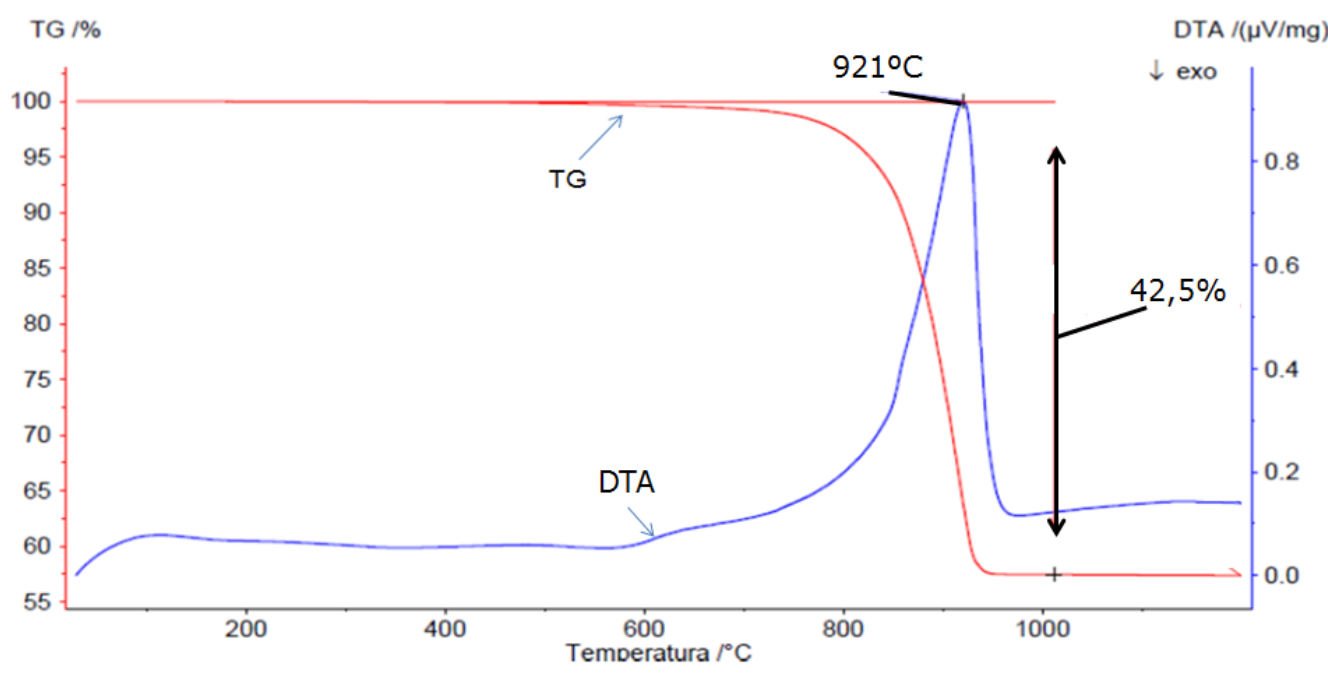

c) Calcário

Figura 1. Termogramas das fontes carbonatadas de $\mathrm{MgO}$ e $\mathrm{CaO}$ 


\subsection{Fabricação do sínter em escala piloto}

O sínter fabricado com a dolomita foi utilizado como referência. Para isso, a massa de retorno adicionada foi igual à massa de saída para 3,1\% de combustível sólido, fixando-o nos demais sínteres e deixando o balanço de retorno (ou rendimento do produto) como variável. As proporções das matérias-primas utilizadas na fabricação dos sínteres pilotos, apresentadas na Tabela 3, foram calculadas mantendo constante no sínter os teores de $\mathrm{MgO}$ e de $\mathrm{MnO}$, bem como a basicidade binária $\left(\mathrm{CaO} / \mathrm{SiO}_{2}\right.$ em 1,7). Coque e antracito foram os combustíveis sólidos usados na proporção de $50 \%$. Esse teste foi realizado em triplicata.

Tabela 3. Proporção das matérias-primas utilizadas na sinterização piloto

\begin{tabular}{|c|c|c|c|c|c|c|}
\hline \multirow{3}{*}{\multicolumn{2}{|c|}{ Matérias-primas }} & \multicolumn{5}{|c|}{ Mistura parcial (\%) } \\
\hline & & \multicolumn{5}{|c|}{ Nível } \\
\hline & & I (referência) & II & III & IV & V \\
\hline \multirow{8}{*}{ Minério de ferro } & A & \multicolumn{5}{|c|}{26,5} \\
\hline & $B$ & \multicolumn{5}{|c|}{15,5} \\
\hline & C & \multicolumn{5}{|c|}{8,6} \\
\hline & $\mathrm{D}$ & \multicolumn{5}{|c|}{8,2} \\
\hline & $E$ & \multicolumn{5}{|c|}{6,7} \\
\hline & $\mathrm{F}$ & \multicolumn{5}{|c|}{3,8} \\
\hline & $\mathrm{G}$ & \multicolumn{5}{|c|}{1,9} \\
\hline & $\mathrm{H}$ & \multicolumn{5}{|c|}{0,7} \\
\hline \multirow{6}{*}{ Fundente } & Calcário & 6,3 & 9,4 & 9,5 & 9,4 & 9,8 \\
\hline & Dolomita & 5,2 & \multicolumn{4}{|c|}{-} \\
\hline & Magnesita A & - & 1,9 & \multicolumn{3}{|c|}{-} \\
\hline & Magnesita B & \multicolumn{2}{|l|}{-} & 1,9 & \multirow{3}{*}{1,9} & \\
\hline & Magnesita C & & & & & - \\
\hline & Magnesita D & & - & & & 1,9 \\
\hline Aglomerante & Cal virgem & \multicolumn{5}{|c|}{2,0} \\
\hline \multirow{6}{*}{ Adições } & Minério de $\mathrm{Mn}$ & 0,4 & 0,3 & 0,3 & 0,3 & 0,4 \\
\hline & Pó do alto-forno & \multicolumn{5}{|c|}{1,0} \\
\hline & Rejeito industrial & \multicolumn{5}{|c|}{1,0} \\
\hline & $\begin{array}{l}\text { Degradado (sínter } \\
\quad<5 \mathrm{~mm} \text { ) }\end{array}$ & \multicolumn{5}{|c|}{10,0} \\
\hline & Pó da sinterização & \multirow{2}{*}{\multicolumn{5}{|c|}{1,0}} \\
\hline & Carepa & & & & & \\
\hline
\end{tabular}

A fabricação do sínter foi realizada em três etapas: (i) aglomeração a frio; (ii) aglomeração a quente (sinterização na panela) e (iii) degradação do sínter.

A primeira etapa, aglomeração a frio, objetivou formar agregados a partir da ação aglomerante da cal virgem e água. Para isso, a mistura total foi levada ao misturador intensivo, visando homogeneizar e iniciar a aglomeração, sendo adicionados $80 \%$ da água total. Em seguida, a mistura prosseguiu para o tambor aglomerador para o crescimento dos agregados. Neste momento, adicionou-se a água restante (20\%). Os parâmetros adotados nestes equipamentos são apresentados na Tabela 4. 
Tabela 4. Parâmetros dos equipamentos utilizados na aglomeração a frio

\begin{tabular}{c|c|c}
\hline Equipamento & Parâmetros & Valor \\
\hline \multirow{4}{*}{ Misturador intensivo } & Tempo de residência & $1 \mathrm{~min}$ \\
\cline { 2 - 3 } & Rotação do elemento misturador & $350 \mathrm{RPM}$ \\
\cline { 2 - 3 } & Diâmetro do elemento misturador & $350 \mathrm{~mm}$ \\
\cline { 2 - 3 } & Proporção da água adicionada & $80 \%$ \\
\hline \multirow{3}{*}{ Tambor } & Tempo de residência & $6 \mathrm{~min}$ \\
\cline { 2 - 3 } & Rotação & $14 \mathrm{RPM}$ \\
\cline { 2 - 3 } & Proporção da água adicionada & $20 \%$ \\
\hline
\end{tabular}

Imediatamente após a aglomeração a frio, determinou-se a umidade para garantir que a mistura total apresentasse $7 \%$. Em seguida carregou-se a mistura aglomerada na panela de sinterização evitando, ao máximo, a compactação do leito.

A segunda etapa, aglomeração a quente ou sinterização, visou submeter a mistura total aglomerada a frio ao processamento térmico para fabricar o bolo de sínter. Com a mistura na panela, iniciou-se a ignição por meio da queima do gás de coqueria (COG) com 0 ar. O tempo final da queima ocorreu a partir da redução de temperatura em $1^{\circ} \mathrm{C}$ em relação à temperatura máxima. Essa temperatura foi medida por um termopar situado abaixo da grelha. Neste momento foi iniciado o resfriamento do bolo de sínter reduzindo a depressão de $1600 \mathrm{mmH}_{2} \mathrm{O}$ para $600 \mathrm{mmH}_{2} \mathrm{O}$, até o termopar (citado anteriormente) indicar $60^{\circ} \mathrm{C}$. Na Tabela 5 são apresentados os parâmetros adotados no processo de sinterização em escala piloto.

Tabela 5. Parâmetros do ensaio de sinterização piloto

\begin{tabular}{c|c}
\hline Parâmetros & Valor \\
\hline Altura da panela & $520 \mathrm{~mm}$ \\
\hline Diâmetro da panela & $300 \mathrm{~mm}$ \\
\hline Volume da panela & $0,0346 \mathrm{~m}^{3}$ \\
\hline Relação ar / COG (Coke Oven Gas) & 5,2 \\
\hline Altura do bedding & $30 \mathrm{~mm}$ \\
\hline Massa do bedding & $3 \mathrm{~kg}$ \\
\hline Tempo de ignição & $1 \mathrm{~min}$ \\
\hline Depressão durante ignição & $600 \mathrm{mmH}_{2} \mathrm{O}$ \\
\hline Depressão durante a queima & $1600 \mathrm{mmH}_{2} \mathrm{O}$ \\
\hline Depressão durante o resfriamento & $600 \mathrm{mmH}_{2} \mathrm{O}$ \\
\hline
\end{tabular}

Após o resfriamento do bolo de sínter piloto, prosseguiu-se para a terceira etapa (degradação do sínter), simulando os esforços exercidos no bolo produzido industrialmente. Para isso, levou-se o bolo no equipamento usado no teste Shatter, deixando-o cair a uma altura de $2 \mathrm{~m}$ para representar o impacto mecânico. Em seguida, foi levado ao tambor usado no teste Tumbler para simular o esforço por abrasão, sendo submetido a 5 voltas.

Posteriormente à degradação, o sínter foi classificado em peneiras com malhas de $50 \mathrm{~mm}$; $25 \mathrm{~mm} ; 10 \mathrm{~mm}$ e $5 \mathrm{~mm}$ para o cálculo dos indicadores produtivos, conforme equações (1) a (5).

$$
\begin{aligned}
& \eta 1=\text { Rendimento produto }(\%)=\frac{>5 \mathrm{~mm} \text { sínter }(\mathrm{kg})-\text { bedding }(3 \mathrm{~kg})}{\text { massa do bolo }(\mathrm{kg})-\text { bedding }(3 \mathrm{~kg})} * 100 \\
& \eta 2=\text { Rendimento mistura total }(\%)=\frac{\text { massa do bolo }(\mathrm{kg})-\text { bedding }(3 \mathrm{~kg})}{\text { massa da mistura total seca }(\mathrm{kg})} * 100
\end{aligned}
$$




$$
\mathrm{FFS}\left(\frac{\mathrm{mm}}{\min }\right)=\frac{\text { altura da camada }(\mathrm{mm})}{\text { tempo de sinterização }(\mathrm{min})}
$$

$$
\text { Densidade }\left(\frac{\mathrm{t}}{\mathrm{m}^{3}}\right)=\frac{\text { massa da mistura napanela }(\mathrm{t})}{\text { volume da panela }\left(\mathrm{m}^{3}\right)}
$$

$$
\text { Produtividade }\left(\frac{t}{\text { dia. } m^{2}}\right)=\text { densidade }\left(\frac{t}{m^{3}}\right) \times \eta_{1} \times \eta_{2} \times F F S\left(\frac{m}{\text { dia }}\right)
$$

Em que:

- FFS é Front Flame Speed (velocidade da frente de queima) e

- densidade é a bulk referente à mistura na panela.

Mediu-se a resistência mecânica ao impacto e a abrasão do sínter utilizando as normas JIS M8711 (Shatter Test) [5] e JIS M8712 (Tumbler Test) [6], respectivamente. O ensaio RDI aplicado ao sínter segue a norma ISO 4696-1 [7].

\subsection{Avaliação microestrutural do sínter}

Para visualizar o estado das partículas fontes de $\mathrm{MgO}$ (dolomita e magnesita) no sínter, foram utilizados os microscópios do tipo óptico (luz refletida) e eletrônico de varredura acoplado com dispositivo para a espectroscopia de energia dispersiva (EDS).

\section{RESULTADOS E DISCUSSÃO}

\subsection{Comportamento das misturas com magnesitas na sinterização piloto}

A composição química dos sínteres fabricados é apresentada na Tabela 6 e os efeitos das misturas com as magnesitas nos indicadores da sinterização piloto são

\begin{tabular}{|c|c|c|c|c|c|c|c|c|c|}
\hline \multicolumn{2}{|c|}{ Fonte de $\mathrm{MgO}$} & Nível & FeT & $\mathrm{FeO}$ & $\mathrm{SiO}_{2}$ & $\mathrm{CaO}$ & $\mathrm{MgO}$ & $\mathrm{Al}_{2} \mathrm{O}_{3}$ & $\mathrm{MnO}$ \\
\hline \multicolumn{2}{|c|}{ Dolomita } & 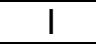 & 57,3 & 2,9 & 5,2 & 8,8 & 1,17 & 1,00 & 0,60 \\
\hline \multirow{4}{*}{ Magnesita } & A & II & 57,9 & 3,3 & 5,2 & 8,6 & 1,14 & 1,07 & 0,60 \\
\hline & $\mathrm{B}$ & III & 56,8 & 3,2 & 5,2 & 8,9 & 6 & 9 & 0,58 \\
\hline & $\mathrm{C}$ & IV & 58 & 3,5 & 5, & 8,7 & 1,14 & 1,16 & 0,52 \\
\hline & $\mathrm{D}$ & $\mathrm{V}$ & 57,8 & 3,3 & 5,4 & 9,0 & 1,14 & 1,04 & 0,64 \\
\hline
\end{tabular}
apresentados na Tabela 7 e nas Figuras 2 a 4.

Tabela 6. Composição química dos sínteres

\begin{tabular}{|c|c|c|c|c|c|}
\hline Nível & I & II & III & IV & V \\
\hline Fonte do MaO & Rolomita & \multicolumn{4}{|c|}{ Magnesita } \\
\hline romle de ivigu & Dolomita & A & $\mathrm{B}$ & $\mathrm{C}$ & $\mathrm{D}$ \\
\hline Mistura total seca $(\mathrm{kg})$ & 71,0 & 71,2 & 71,8 & 72,3 & 70,0 \\
\hline Bolo de sínter (kg) & 67,8 & 68,0 & 67,4 & 69,2 & 66,9 \\
\hline Sínter >5 mm (kg) & 53,5 & 54,2 & 53,7 & 56,2 & 51,2 \\
\hline Sínter $<5 \mathrm{~mm} \mathrm{(kg)}$ & 14,3 & 13,8 & 13,7 & 13,0 & 15,7 \\
\hline Tempo de sinterização (min) & 27,3 & 26,0 & 25,5 & 25,6 & 26,8 \\
\hline Balanço de retorno (input/output) & 1,04 & 1,10 & 1,10 & 1,19 & 0,94 \\
\hline
\end{tabular}

Tabela 7. Resultados da sinterização piloto 


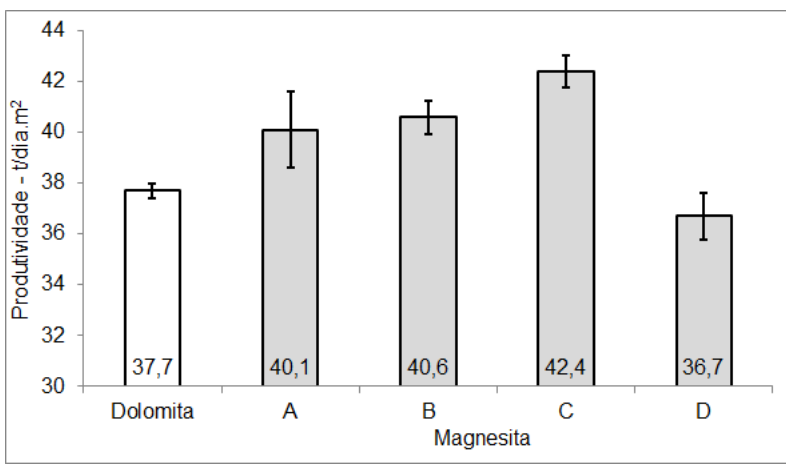

a) Produtividade (nível de confiança: 95\%)

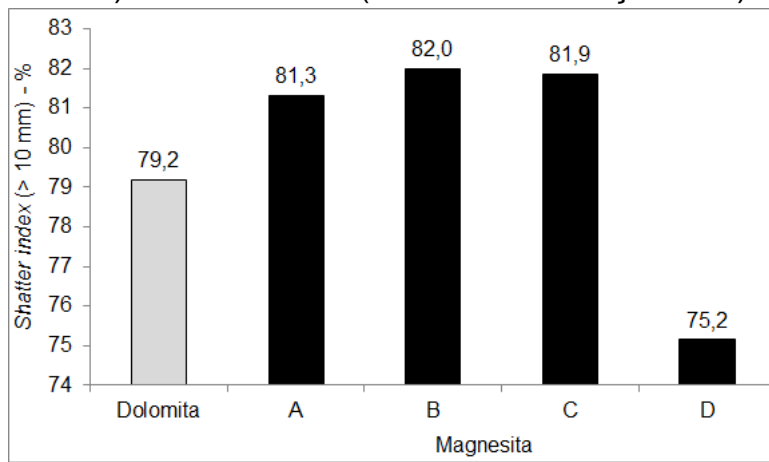

c) Shatter index

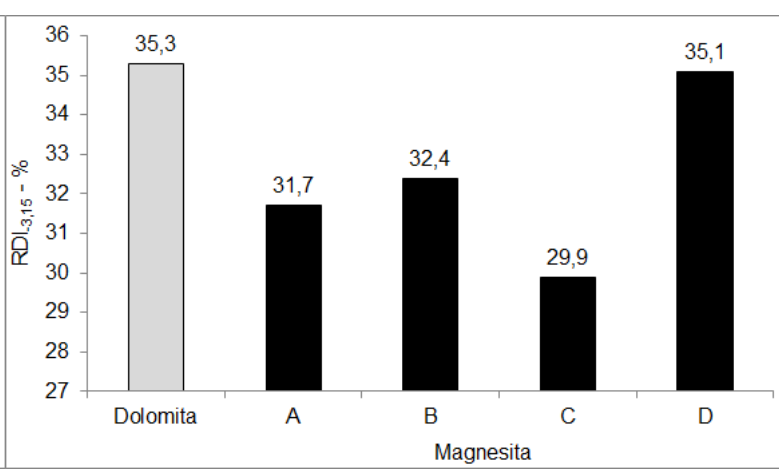

b) $\mathrm{RDI}_{-3,15}$

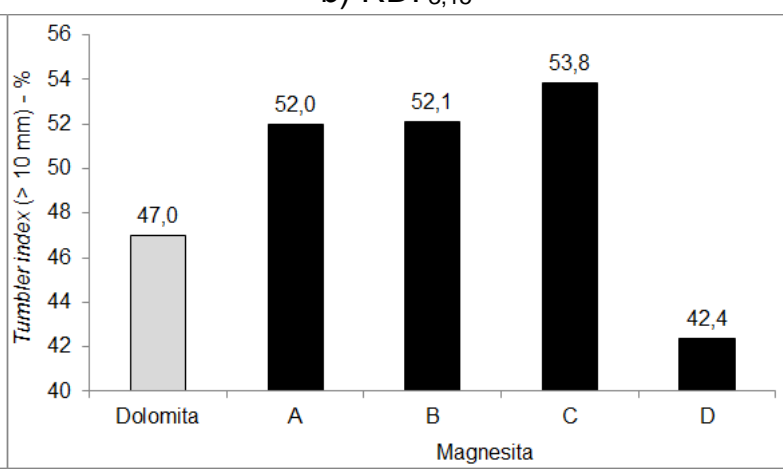

d) Tumbler index

Figura 2. Indicadores produtivos da sinterização piloto e da qualidade do sínter.

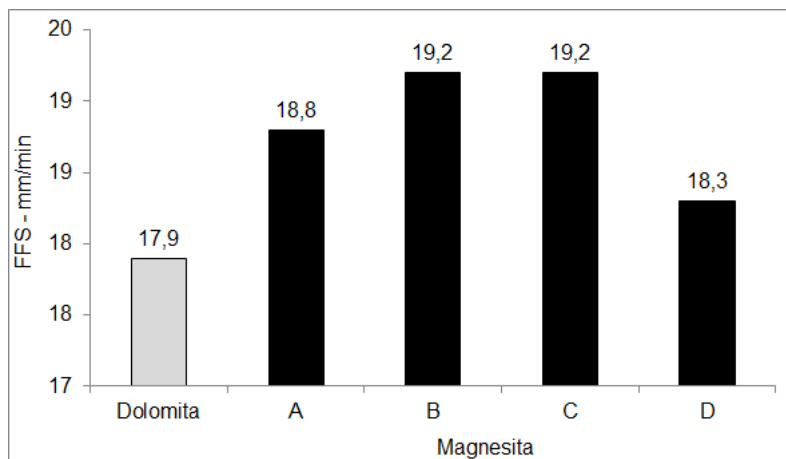

a) FFS

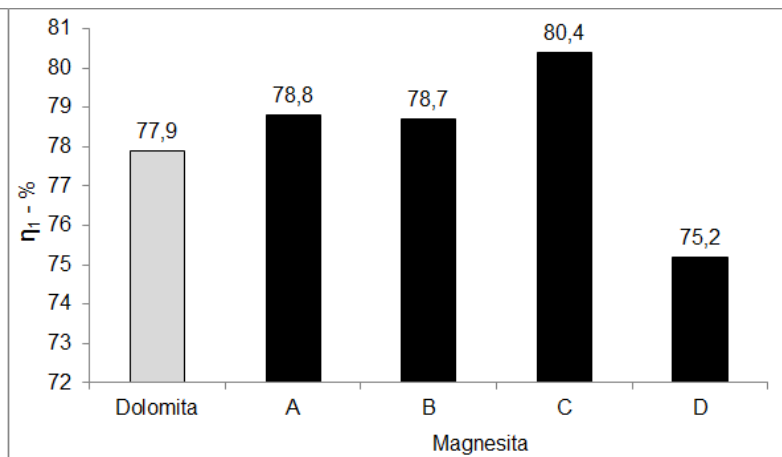

b) Rendimento do produto

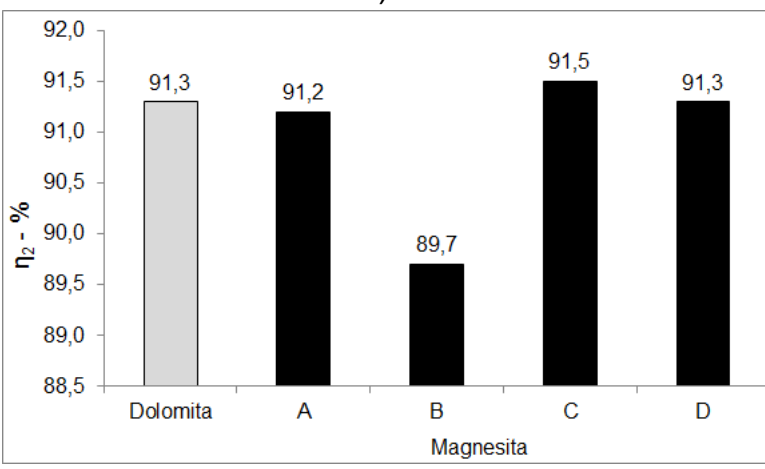

c) Rendimento da mistura

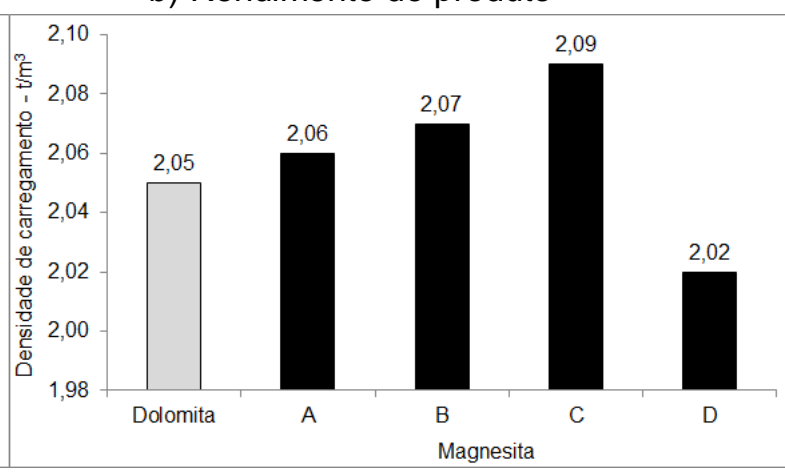

d) Densidade

Figura 3. Fatores que compõem a equação da produtividade. 


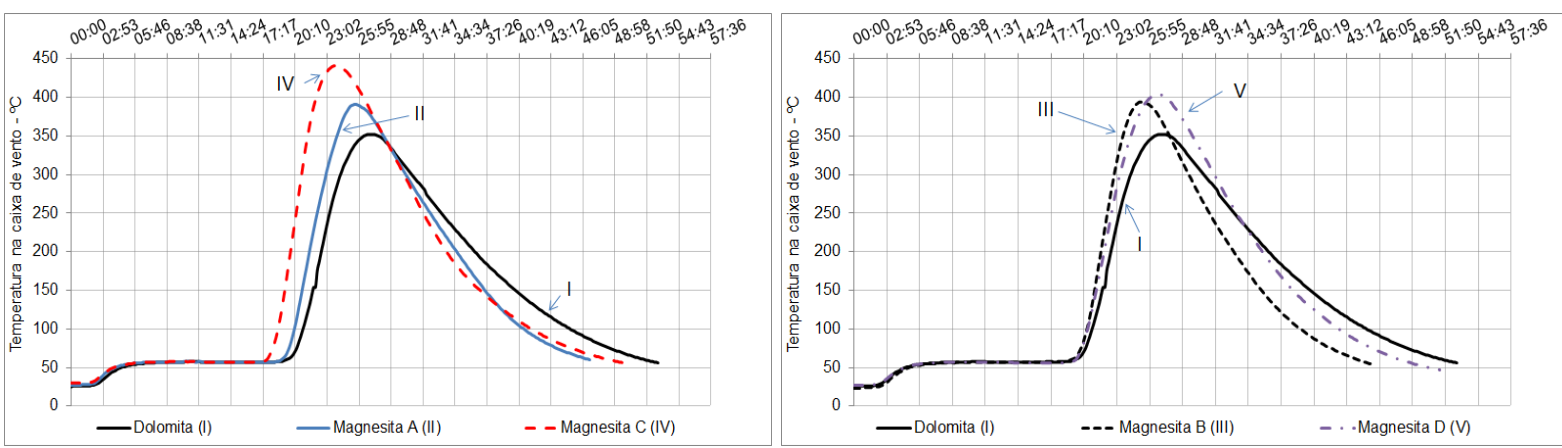

Figura 4. Perfil térmico medido na caixa de vento da máquina piloto.

A substituição da dolomita por magnesitas com granulometria similar ( $A, B$ e $C)$ melhorou notadamente o nível produtivo da sinterização piloto e a qualidade do sínter. Por outro lado, a alteração pela Magnesita D prejudicou esses indicadores, mostrando que a granulometria mais fina que a da dolomita é inadequada para o processo.

O aumento da produtividade decorreu do deslocamento mais rápido da frente de queima e do maior rendimento do produto. No caso da Magnesita $D$, houve ligeiro aumento da velocidade da frente de queima. Mas, o rendimento do produto foi consideravelmente reduzido, refletindo na queda da produtividade.

No que tange a resistência mecânica do sínter, a troca pelas Magnesitas A, B e C beneficiou os seus indicadores, tumbler index e shatter index. Todavia, a Magnesita D fragilizou consideravelmente o sínter, conforme seus valores de tumbler e shatter.

Finalmente, o indicador metalúrgico RDI melhorou com as Magnesitas A, B e C e não foi alterado de maneira significativa com a Magnesita D. Segundo Inazumi [2], esse indicador é melhorado com a adição $\mathrm{MgO}$ que ao reagir com ferro estabiliza a magnetita secundária, reduzindo a formação da hematita secundária esqueletiforme, tida como precursora desse fenômeno.

Os perfis térmicos do processo de sinterização com as magnesitas atingiram patamares de temperatura acima daquela mostrada pelo sínter com a dolomita. Isto é um reflexo de que houve sobra de energia no processo e, devido a isto, foi observada melhora na resistência mecânica e rendimento do sínter.

Entretanto, mesmo com o ambiente propício para a melhora desses indicadores, o efeito negativo da maior superfície específica da Magnesita D mostrou ser superior àquele ambiente. Portanto, o calor não foi suficiente para garantir o nível de qualidade e produtivo da sinterização, obtido no nível referência (I - dolomita). Além disso, a forma como a matéria-prima se comporta na microestrutura do sínter indica ser tão importante quanto o calor necessário para a sua fabricação.

\subsection{Análise microestrutural dos sínteres}

As microestruturas dos sínteres fabricados com a dolomita e com a Magnesita C (escolhido em razão do melhor desempenho na sinterização piloto) revelaram diferenças e semelhanças que explicam o comportamento mecânico dos sínteres.

$\mathrm{Na}$ Figura 5 é mostrada a Região A no sínter com a dolomita parcialmente reagida que pôde ser dividida em quatro partes. A partir do mapeamento, EDS e morfologia, Figuras 6 e 7 e Tabela 8, foi possível estimar algumas fases. Notou-se a presença de dois tipos de magnetita com morfologia diferente, sendo uma (Mg1) mais uniforme que a outra (Mg2). De acordo com Higuchi [8] ambas são soluções sólidas 
de magnésio ferrita, contudo, de origens distintas, sendo a Mg1 oriunda da difusão entre o magnésio e a hematita durante aquecimento e a Mg2 oriunda da precipitação do líquido de sinterização. No caso do sínter com a magnesita, também foi possível distinguir quatro partes na Região $\mathrm{B}$ da partícula fonte de $\mathrm{MgO}$ parcialmente reagida (Figura 8). O mapeamento e a análise pontual da composição química (EDS) são mostrados nas Figuras 9 e 10 e na Tabela 9.

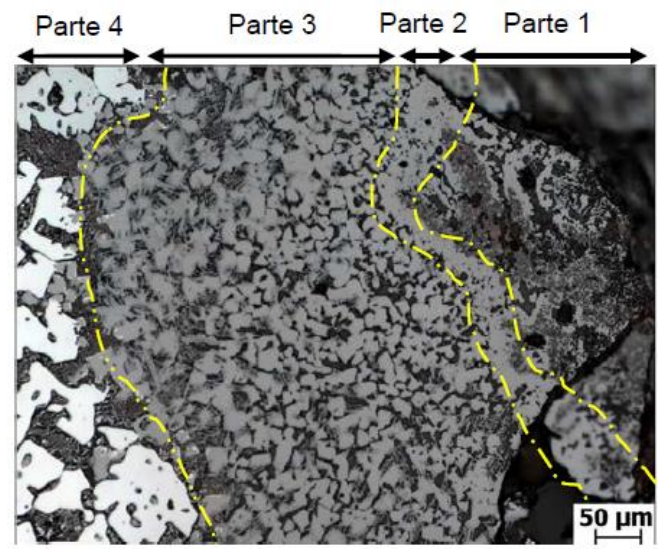

Figura 5. Região A do sínter mostrando uma partícula de dolomita parcialmente reagida (Parte 1).
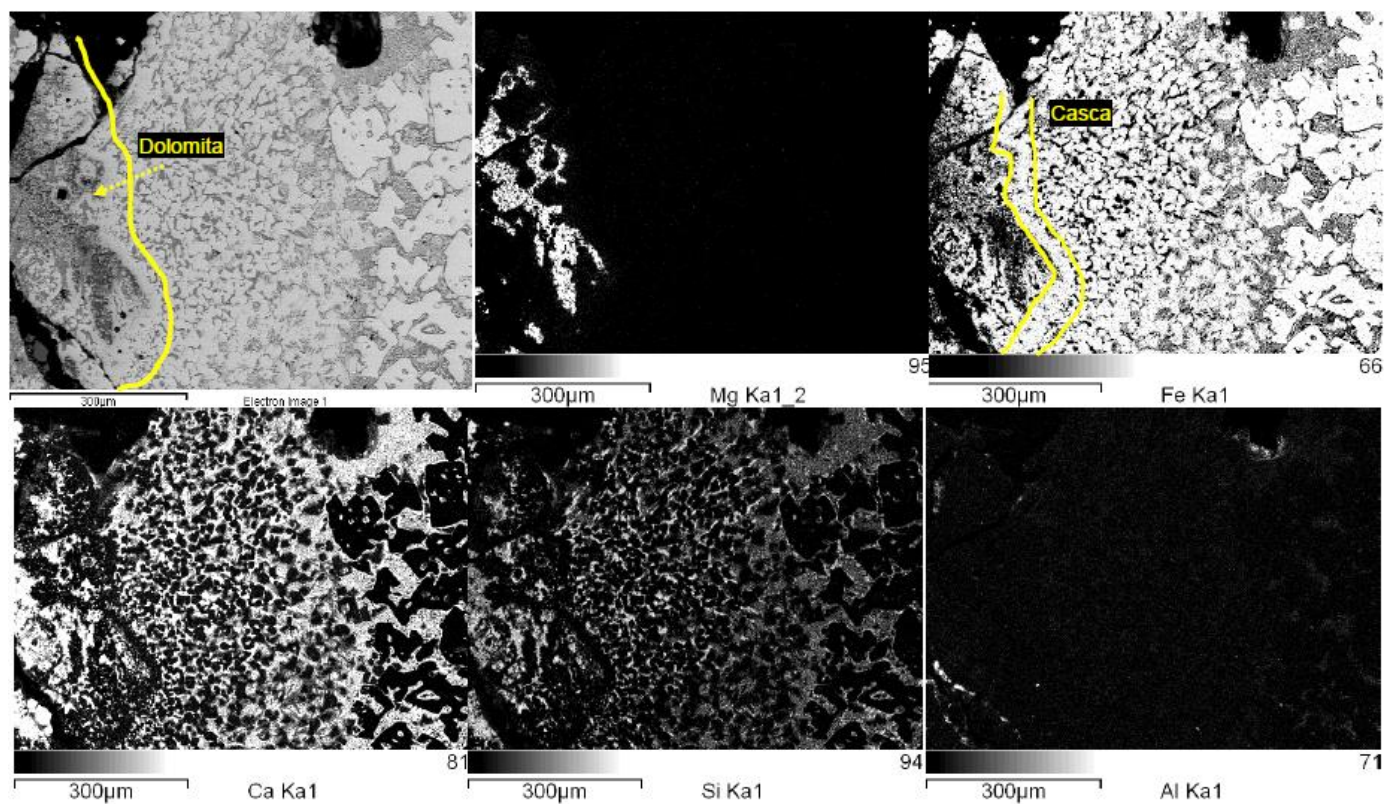

Figura 6. Mapeamento da Região A do sínter com dolomita.

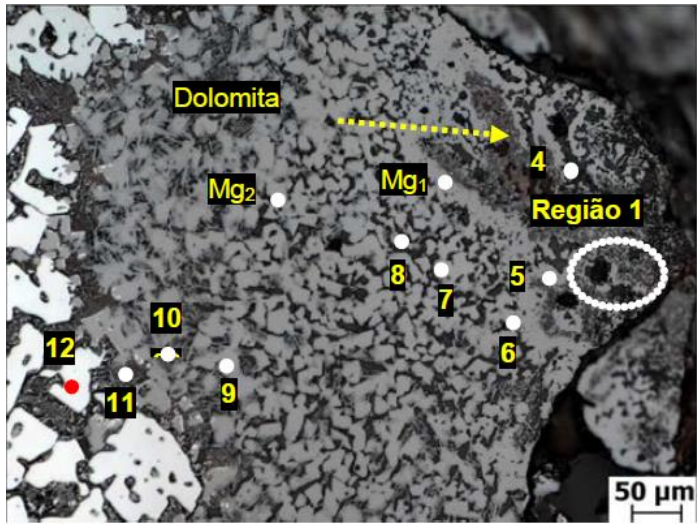

a) Geral

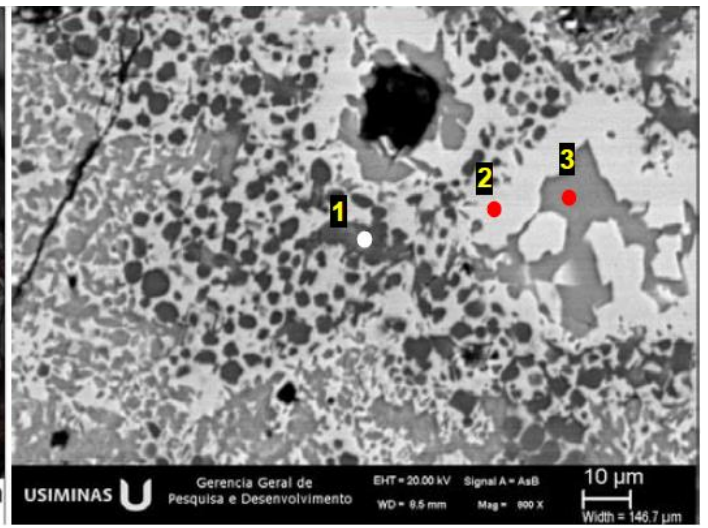

b) Região 1 
Figura 7. EDS aplicado em pontos da Região A do sínter com dolomita.

Tabela 8. Composição química determinada por EDS na região da dolomita

\begin{tabular}{|c|c|c|c|c|c|c|c|}
\hline Parte & Ponto & $\mathrm{Fe}$ & $\mathrm{Mg}$ & $\mathrm{Ca}$ & Si & Al & Fase (possível) \\
\hline \multirow{4}{*}{1 (dolomita) } & 1 & 11,4 & 52,0 & 0,3 & 0,1 & 0,2 & \multirow{2}{*}{ Magnésio ferrita } \\
\hline & 2 & 51,7 & 13,8 & 1,7 & 0,1 & 1,1 & \\
\hline & 3 & 1,5 & 0,1 & 44,3 & 17,0 & 0,0 & \multirow{2}{*}{ Silicato de cálcio } \\
\hline & 4 & 1,6 & 0,1 & 45,7 & 17,3 & 0,1 & \\
\hline \multirow[b]{2}{*}{2 (casca) } & 5 & 58,7 & 9,4 & 1,4 & 0,1 & 0,8 & \multirow{3}{*}{$\begin{array}{c}\text { Magnetita } \\
\text { (Magnésio ferrita - Mg1) }\end{array}$} \\
\hline & 6 & 58,7 & 6,5 & 2,0 & 0,1 & 0,8 & \\
\hline \multirow{5}{*}{3} & 7 & 63,1 & 5,5 & 2,0 & 0,1 & 0,6 & \\
\hline & 8 & 2,3 & 0,1 & 45,1 & 17,0 & 0,0 & Silicato de cálcio \\
\hline & 9 & 63,6 & 5,1 & 2,0 & 0,1 & 0,5 & $\begin{array}{c}\text { Magnetita } \\
\text { (Magnésio ferrita - Mg2) }\end{array}$ \\
\hline & 10 & 51,1 & 1,0 & 11,5 & 3,8 & 1,4 & \multirow{2}{*}{$\begin{array}{c}\text { Silico Ferrite of Calcium } \\
\text { Aluminum (SFCA) }\end{array}$} \\
\hline & 11 & 37,4 & 0,0 & 19,6 & 8,0 & 0,4 & \\
\hline 4 & 12 & 71,1 & 0,0 & 0,2 & 0,0 & 0,4 & Hematita secundária \\
\hline
\end{tabular}

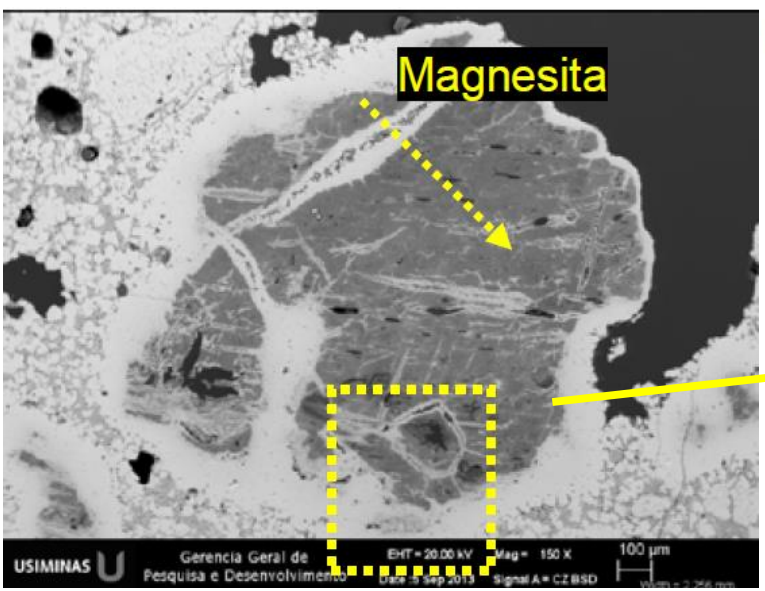

a) Geral

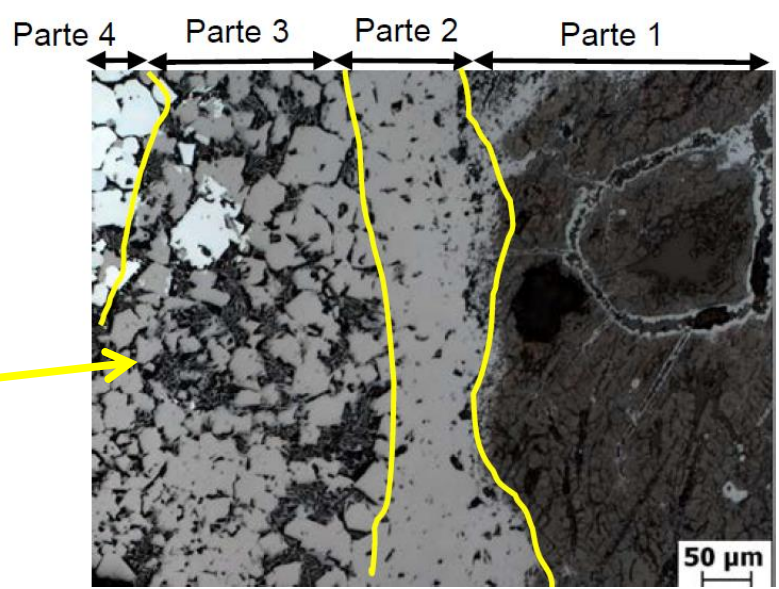

b) Região B

Figura 8. Região do sínter com uma partícula de magnesita parcialmente reagida.
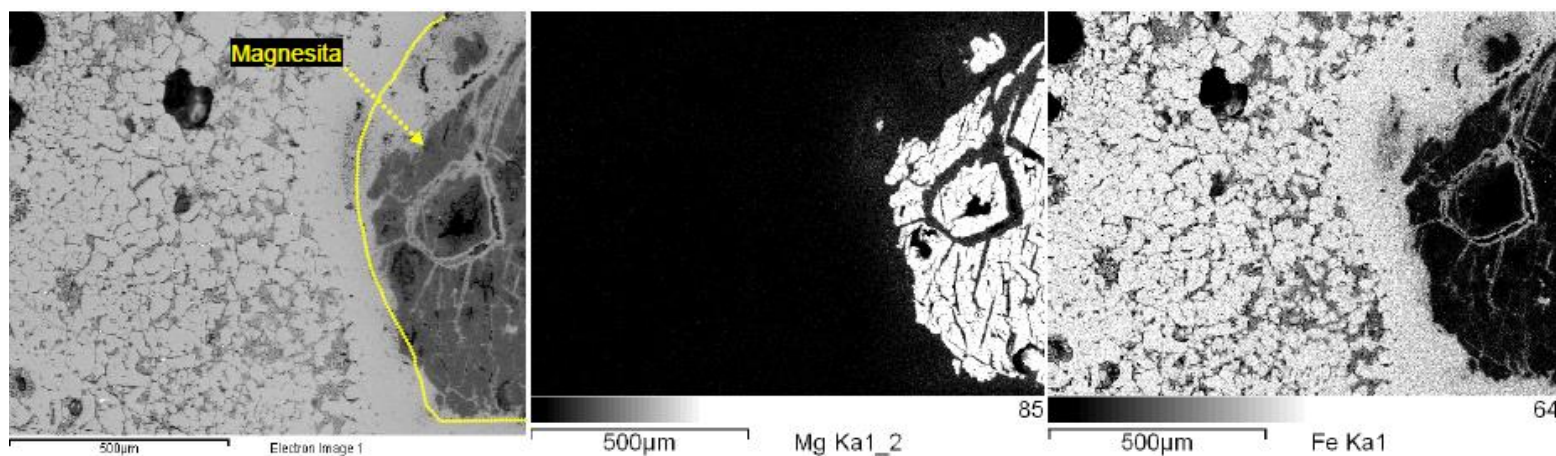

$500 \mu \mathrm{m} \quad M g$ Ka1_2

$500 \mu \mathrm{m}$

Fe Ka1
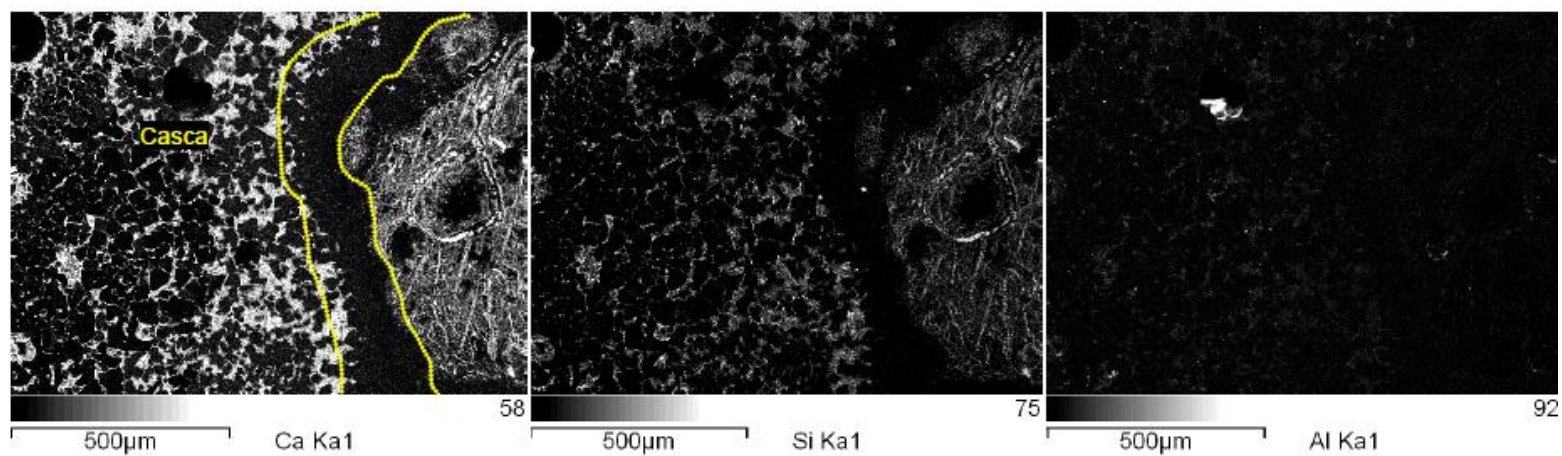

Figura 9. Mapeamento da Região B do sínter com magnesita 


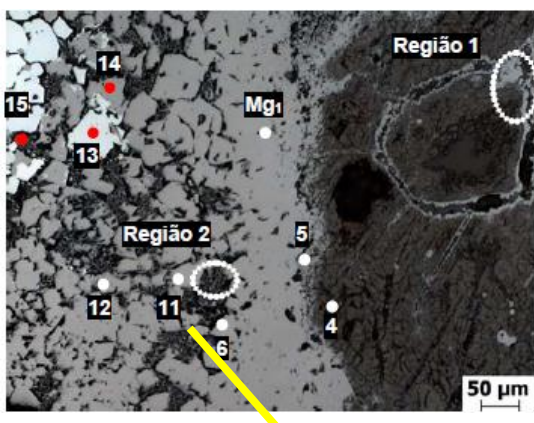

a) Região $B$

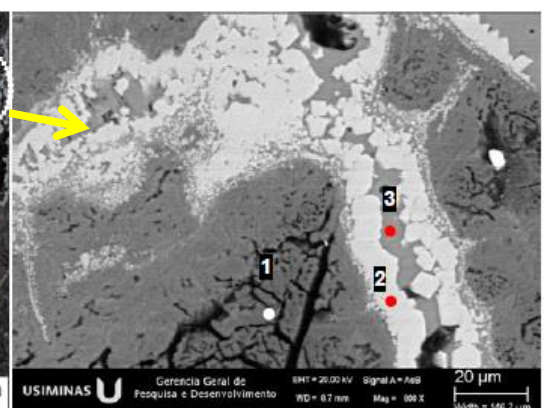

b) Região 1

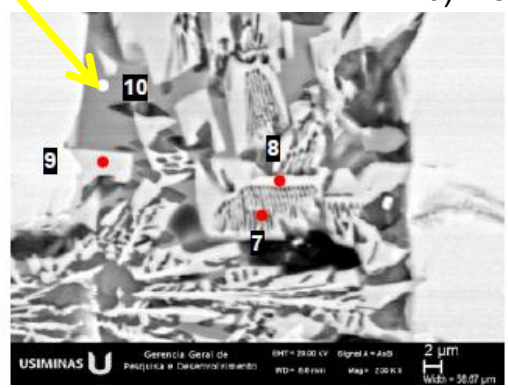

c) Região 2

Figura 10. EDS aplicado em pontos da Região B do sínter com magnesita.

Tabela 9. Composição química determinada por EDS na região da magnesita

\begin{tabular}{|c|c|c|c|c|c|c|c|}
\hline Parte & Ponto & $\mathbf{F e}$ & Mg & $\mathrm{Ca}$ & Si & Al & Fase (possível) \\
\hline \multirow{4}{*}{1 (magnesita) } & 1 & 2,0 & 58,9 & 1,0 & 0,1 & 0,1 & Óxido de magnésio \\
\hline & 2 & 52,6 & 10,8 & 1,7 & 0,4 & 1,6 & $\begin{array}{c}\text { Magnetita } \\
\text { (Magnésio ferrita - Mg1) }\end{array}$ \\
\hline & 3 & 1,3 & 7,0 & 33,2 & 18,1 & 0,0 & Silicato de cálcio \\
\hline & 4 & 7,7 & 37,4 & 9,0 & 5,0 & 0,3 & Óxido de magnésio \\
\hline \multirow{2}{*}{2 (casca) } & 5 & 58,8 & 7,9 & 0,9 & 0,2 & 1,3 & \multirow{2}{*}{$\begin{array}{c}\text { Magnetita } \\
\text { (Magnésio ferrita - Mg1) }\end{array}$} \\
\hline & 6 & 66,5 & 2,1 & 1,6 & 0,0 & 0,7 & \\
\hline \multirow{8}{*}{3} & 7 & 39,5 & 0,1 & 15,1 & 6,5 & 2,4 & \multirow{4}{*}{$\begin{array}{l}\text { Silico Ferrite of Calcium } \\
\text { Aluminum (SFCA) }\end{array}$} \\
\hline & 8 & 41,4 & 0,2 & 18,7 & 6,7 & 1,8 & \\
\hline & 9 & 48,6 & 0,4 & 11,8 & 4,8 & 2,3 & \\
\hline & 10 & 35,4 & 0,2 & 17,9 & 7,6 & 1,8 & \\
\hline & 11 & 65,9 & 1,5 & 2,1 & 0,0 & 0,6 & \multirow{2}{*}{ Magnetita secundária } \\
\hline & 12 & 66,3 & 1,3 & 1,7 & 0,1 & 0,7 & \\
\hline & 13 & 68,4 & 0,0 & 0,1 & 0,1 & 0,6 & Hematita secundária \\
\hline & 14 & 67,0 & 1,3 & 1,7 & 0,1 & 0,6 & Magnetita secundária \\
\hline 4 & 15 & 35,6 & 0,2 & 16,6 & 6,6 & 4,0 & Bolsa de escória \\
\hline
\end{tabular}

Partículas parcialmente reagidas de minério de ferro na microestrutura do sínter são necessárias para se atingir o comportamento metalúrgico mais adequado ao altoforno. Contudo, é desejável que as partículas dos fundentes, principalmente de calcário, participem completamente das reações, aumentando o volume do líquido de sinterização.

Por outro lado, o MgO possui dificuldade em ser dissolvido no líquido de sinterização em razão da afinidade química entre o magnésio e o ferro, conforme pontuado por Inazumi [2] e verificado nos resultados desse estudo. Higuchi [8] complementa que na dolomita ocorre a formação da magnetita densa (solução sólida Mg1) ao seu redor que encapsula o cálcio, impedindo-o de participar da matriz de escória que enrijece o sínter. Na magnesita, também, formou-se a casca (Mg1), a principio identificada ao microscópio óptico como magnetita. Porém, ao MEV mostrou se tratar da solução sólida magnésio ferrita. 
Apesar de ambas ocorrerem a formação da casca, somente no caso da dolomita houve impedimento do cálcio em formar a matriz de escória. Entretanto, a substituição da dolomita pela magnesita, ao implicar que todo o cálcio fosse oriundo do calcário, possivelmente elevou o volume, o teor de cálcio no líquido e a proporção de SFCA, favorecendo à resistência mecânica do sínter.

\section{CONCLUSÃO}

Foi investigado, em escala piloto, o efeito da substituição da dolomita por Magnesitas (A, B, C e D) nos indicadores de processo da sinterização.

- A utilização de uma fonte exclusiva de MgO (magnesita) com granulometria similar ( $\mathrm{A}, \mathrm{B}$ e $\mathrm{C})$ à da dolomita melhorou a produtividade, consideravelmente a resistência mecânica e o RDI do sínter. Entretanto, o tipo (Magnesita D) com alta superfície específica prejudicou esses indicadores (exceto o RDI) mesmo com o ambiente propício (sobra de calor) para a melhora desses indicadores.

- A substituição da dolomita pela magnesita, ao implicar que todo o cálcio fosse oriundo do calcário e evitar o encapsulamento do cálcio ocorrido com o uso da dolomita, possivelmente elevou o volume, o teor de cálcio no líquido e a proporção de SFCA, favorecendo à resistência mecânica do sínter.

\section{Agradecimentos}

Agradecimento especial aos engenheiros Edilson Pinto Honorato e José de Souza Carvalho.

\section{REFERÊNCIAS}

1 Geerdes M, Toxopeus HE, Vliet CVD. Modern blast furnace ironmaking - an introduction. Segunda edição. Mekelweg: IOS Press Delft University Press; 2009.

2 Inazumi T. Applied mineralogical studies on self-fluxing sinter of iron ores: relationship between the mineralogical properties of hematite and size degradability during the reduction of sinter [tese de doutorado]. Universidade de Tóquio; 1975.

3 Barrie DJ, Carmichael IF, Kinloch ED. Iron Steel Institute. In: Panigrahy. S. C.; Verstraeten, P, Dilewijns, J. Effect of MgO addition on strenght characteristics of iron ores sinter. Ironmaking and steelmaking. 1984;11(1):17-22.

4 Scudeller LAM, Silva BV, Honorato EP, Tetti U. Utilização da dolomita como fonte exclusiva de $\mathrm{MgO}$ nas sinterizações da Usiminas. In: Seminário de Redução de Minério de Ferro e Matérias-Primas. Anais do 39 Simpósio Brasileiro de Minério de Ferro; 2009; Ouro Preto, Brazil. São Paulo: ABM; 2010. p.1-11.

5 Japanese Industrial Standard. JIS M 8711: test method for determination of shatter strength of iron ore sinter. Tóquio: JIS; 1987.

6 Japanese Industrial Standard. JIS M 8712: Test method for determination of tumbler strength of iron ores. Tóquio: JIS; 1993.

7 International Organization for Standardization. ISO 4696-1: Iron ores for blast furnace feedstocks: determination of low-temperature reduction-disintegration indices by static method - Part1: reduction with CO, CO2, H2 and N2. Genebra: ISO;2007.

8 Higuchi K, Tanaka T, Sato T. Reaction behavior of dolomite accompanied with formation of magnetite solid solution in iron ore sintering process. ISIJ International. 2007;47(5):669-678. 